\title{
New light rail transit and active travel: A longitudinal study
}

\author{
Andy Hong ${ }^{1}$, Marlon G. Boarnet ${ }^{1}$, Doug Houston ${ }^{2}$ \\ ${ }^{1}$ Price School of Public Policy, University of Southern California, Los Angeles, CA \\ ${ }^{2}$ Department of Planning, Policy and Design, School of Social Ecology, \\ University of California, Irvine, CA
}

\begin{abstract}
We use panel data to investigate the before-and-after impact of a new light rail transit line on active travel behavior. Participants were divided into a treatment group and a control group (residing $<1 / 2$ mile and $>1 / 2$ mile from a new light rail transit station, respectively). Self-reported walking ( $n=204)$ and accelerometermeasured physical activity $(n=73)$ were obtained for both groups before and after the new light rail transit opened. This is the first application of an experimental-control group study design around light rail in California, and one of the first in the U.S. Our panel design provides an opportunity for stronger causal inference than is possible in the much more common study designs that use cross-sectional data. It also provides an opportunity to examine how an individual's previous activity behavior moderates the role that new light rail transit access plays in promoting active travel behavior. The results show that, when not controlling for subject's before-opening walking or physical activity, there was no significant relationship between treatment group status and after-opening walking or physical activity. However, when controlling for an interaction between baseline walking/physical activity and treatment group membership, we found that living within a half-mile of a transit station was associated with an increase in walking and physical activity for participants who had previously low walking and physical activity levels. The results were opposite for participants with previously high walking and physical activity levels. Future policy and research should consider the possibility that sedentary populations may be more responsive to new transit investments, and more targeted approaches in transit service would be needed to encourage people to make healthy travel choices.
\end{abstract}

Key Words:

Physical activity; walking; transit; longitudinal; past behavior; travel behavior 


\section{Introduction}

A sedentary lifestyle is a growing concern in the United States. It is a major risk factor for obesity and a variety of chronic diseases, such as coronary heart disease, type 2 diabetes, and breast and colon cancers (Lee et al., 2012; WHO, 2009). However, the share of adults and children engaged in physically active travel for both work and leisure has declined sharply over the past decades in the United States (Bassett et al., 2008; Brownson et al., 2005). Recognizing this problem with sedentary lifestyle, public health and urban planning researchers have turned to the potential role of the built environment to change behavior and create a pathway to a physically active lifestyle (Brownson et al., 2009; Frank et al., 2006). This new line of research focusing on the potential role of the built environment in promoting active travel behavior had a profound influence on the current research and practice in urban planning and transportation (Badland and Schofield, 2005; Bors et al., 2009; Sallis et al., 2004).

One area that is receiving increasing attention in the field of urban planning and transportation is the role of public transit in promoting more active and healthy travel choices (Morency et al., 2011; Stokes et al., 2008). In recent years, many local and regional governments have built new transit systems, and an increasingly common secondary justification for those systems is the promotion of active lifestyles (US DOT, 2014; Zheng, 2008). Previous research has found a positive association between frequent transit use and moderate physical activity (Besser and Dannenberg, 2005; Lachapelle et al., 2011; Rissel et al., 2012). Living close to a transit station was also found to increase the odds of utilitarian walking (McCormack et al., 2008). However, these studies were based on cross-sectional data, showing only a correlation with the observed relationships. Because of the cross-sectional nature of most studies, it is still unclear whether changes in the built environment through new transit investments can lead to a meaningful behavioral change (Bauman et al., 2002).

We fill a gap in the literature by presenting results from one of the first longitudinal studies of travel behavior change before and after the construction of a new light rail line. Our longitudinal study design allows stronger causal inference than cross-sectional data. Our research examines the role of individual's previous walking and physical activity levels in moderating any "treatment effect" of new light rail transit on after-opening walking and physical activity. The use of past behavior as a moderator in a longitudinal study of the impact of new light rail is novel in the literature. In addition, we use more robust measurement of active travel behavior- self-reported walking and accelerometer-based physical activity, and our findings are similar for both measures.

\section{Literature Review}

Previous research on the impacts of transit investments suggest that transit is positively associated with active travel behavior (Besser and Dannenberg, 2005; Lachapelle and Noland, 2012; Rissel et al., 2012). However, most research on this area consists of cross sectional studies, making it difficult to assess causal relationships. Longitudinal studies can provide stronger evidence on the impacts of new transit 
investments and overcome concerns over the influence of residential selection on travel behavior (Cao et al., 2006). However, longitudinal evaluations of the travel impacts associated with new light rail transit are still rare. To our knowledge, only two studies have longitudinally examined the effects of a new light rail transit line on active travel behavior. Brown and Werner $(2008,2007)$ used a pre-post study design to examine the impact of a new light rail line on 51 residents in Salt Lake City, Utah. They found that using the new transit service was associated with an increase in moderate physical activity, but no statistically significant association was found between proximity to the transit stations and physical activity. Using longitudinal samples from Charlotte, North Carolina, MacDonald et al.(2010) found a strong association between light rail use and body mass index (BMI) and obesity. However, they found only a marginally significant association between light rail use and the odds of meeting recommended physical activity. The results from the previous studies suggest that light rail transit may help overcome some of the barriers to engage in active travel, but it is still unclear whether exposure to new transit service has any meaningful impacts on residents' active travel behavior. We contribute to the literature by extending the scope of longitudinal, pre-post studies of new light rail with our case in Los Angeles.

Drawing from a more general literature on the relationship between the built environment and physical activity, researchers have studied a broad range of factors influencing physical activity, including social and physical environments as well as individual psychological factors, such as environmental perceptions and cognitive behavioral attributes (Carlson et al., 2012; Handy et al., 2002; Kerr et al., 2010; McNeill et al., 2006; Saelens et al., 2003; Timperio et al., 2006). Over the past several decades, behavioral change models, such as the health belief model (HBM) and the theory of planned behavior (TPB), have gained popularity in physical activity research and practice (Glanz et al., 2008; King et al., 2002). Among the most prominent theory in the context of the built environment and physical activity is the ecological model which encompasses interpersonal, social, and physical dimensions of activity promotion (Sallis et al., 2006). This model has been widely used by urban planners and policy makers because it enables integration of existing land use and transportation policies into physical activity promotion, contributing towards creating more sustainable and healthier lifestyles (Bauman et al., 2002; Pickett and Pearl, 2001; Sallis et al., 2006).

Despite much work on theory development, potential mediators and moderators of the built environment and physical activity have been understudied (King et al., 2002). One particular area that has received relatively little attention in studies of the built environment and active travel behavior is the role of past behavior, although past behavior has been a focus in closely related research areas. Past behavior has been actively discussed among researchers studying the theory of reasoned action (TRA), theory of planned behavior (TPB), and habitual travel behavior (Ajzen and Fishbein, 1980; Ajzen, 1991; Gärling and Axhausen, 2003). Previous studies have consistently found an independent influence of the frequency of past behavior across a range of behaviors, such as drug use, school attendance, television watching, and recycling behavior (Bentler and Speckart, 1979; Fredricks and Dossett, 1983; Ouellette and Wood, 1998). In particular, past physical activity behavior has been found to influence habit formation, and thus influence intentions to engage in later physical activity (Aarts et al., 1997; Hagger, 2001). Although there is an on-going debate whether past behavior can directly predict later behavior (Ajzen, 2002), studies 
have consistently found that past behavior has a significant residual effect beyond cognitive behavioral constructs (e.g. intentions and perceived behavioral control) while improving model performance and predictability (Bamberg et al., 2003; Hagger, 2001; Norman et al., 2000; Verplanken and Melkevik, 2008; Yordy and Lent, 1993). However, transportation and urban planning research has rarely examined the role of past behavior in explaining the relationship between the built environment and active travel behavior (Gardner, 2009; Thøgersen, 2006).

In this study, we hypothesize that 1) transit proximity, or exposure to new transit service, is positively associated with active travel behavior (self-reported walking and accelerometer-based physical activity); and that 2) the relationship between transit proximity and active travel behavior will be moderated by past behavior, specifically baseline walking trips and physical activity measured before the new light rail transit opened. This study provides stronger evidence on causality by using a natural experiment and longitudinal observations to evaluate individual travel behavior outcomes before and after construction of a new light rail transit system. Compared to the two previous longitudinal studies which relied on either accelerometry data (Brown and Werner, 2007) or survey-derived physical activity measures (MacDonald et al., 2010), we employed more robust measurement of active travel behaviorself-reported walking trips and accelerometry data. Regarding the second hypothesis, this study takes a cue from the theory of planned behavior by focusing on the role of baseline walking and physical activity as possible moderators of the effect of transit proximity on post-opening changes in active travel behavior. To our knowledge, no studies have examined the moderating effect of past behavior on the impact of new light rail transit on active travel behavior. This study makes an important contribution to what is known about the relationship between public transit and active travel behavior by leveraging a longitudinal research design, using two different active travel measures, and examining the role of baseline walking and physical activity as a moderator of the effect of new light rail transit access.

\section{Methods}

\subsection{Study area}

The study neighborhood is located along the Expo light rail line (Expo Line) in south Los Angeles. This new light rail line extends south and west from downtown Los Angeles, eventually reaching downtown Santa Monica upon completion of Phase II (expected Phase II completion by 2016). The present study only includes the Phase I construction of the Expo Line connecting downtown Los Angeles and Culver City, which was opened in stages in April and June 2012. Figure 1 shows examples of the neighborhoods around the light rail stations before and after the construction of the Expo Line, obtained from time-lapsed images provided by Google Street View. Figure 1a shows the changes in neighborhood around Western Station (at-grade platform), and Figure 1b shows the neighborhood around La Cienega Station (elevated platform). Note that the neighborhoods after the construction of the light rail transit had better landscaping elements and nonmotorized facilities, such as dedicated bicycle lanes and improved sidewalks. These added urban design 
elements around the stations seemed to provide more pleasant and welcoming environments to pedestrians and bicyclists.
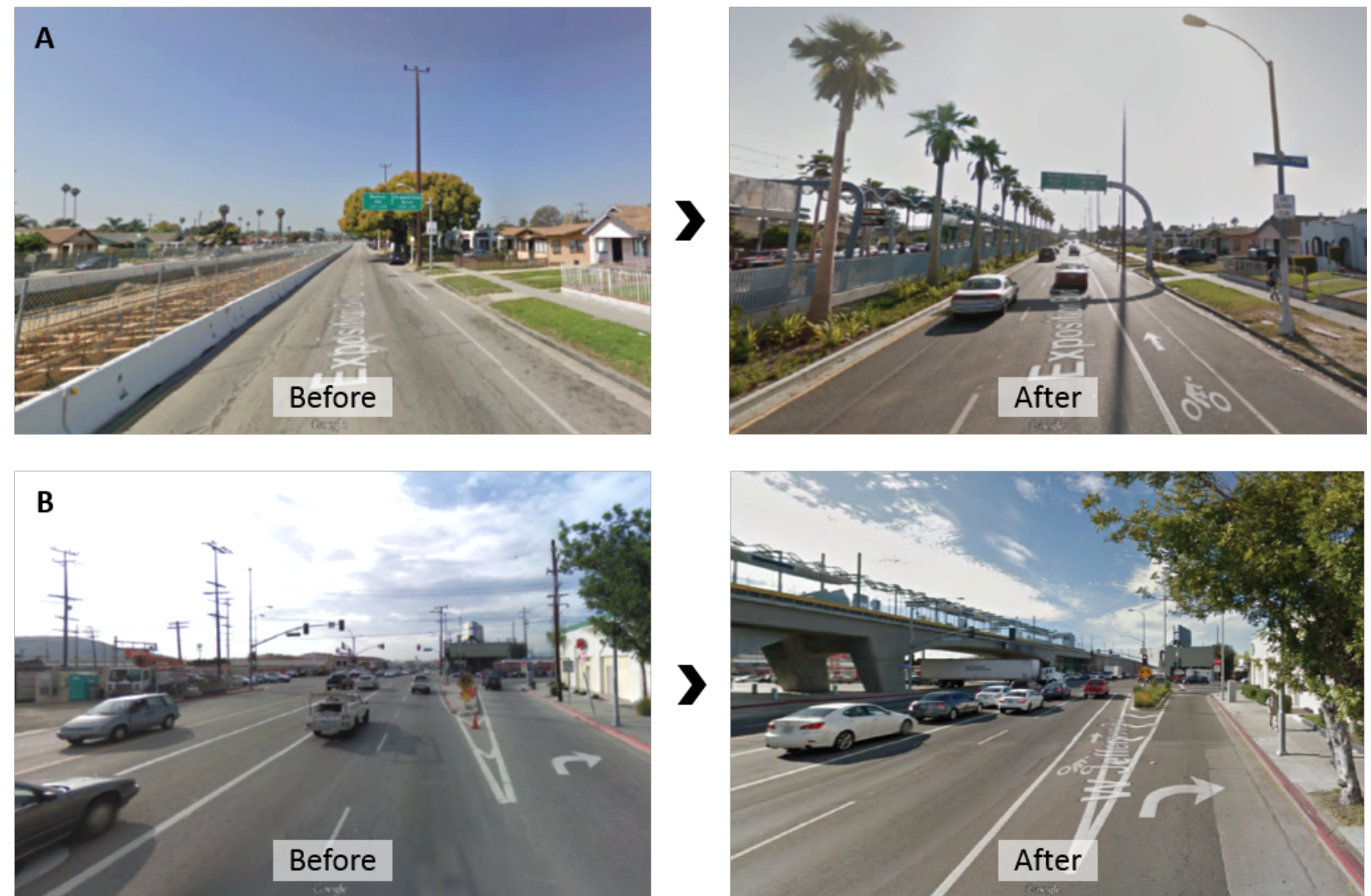

Figure 1. Neighborhoods around Western Station (A); and La Cienega Station (B) before and after the Expo Line, Los Angeles, CA

Source: Courtesy of Google Maps

Figure 2 illustrates the study area including the approximate home location of participants in the treatment group (circled areas) and participants in the control group (the area extending in the broader outline beyond those circles and toward the west and south). The treatment group is defined as residents living within $1 / 2$ mile of a new Expo Line station; and the control group as residents living farther away from a station. A half-mile boundary is considered a typical catchment area within which most transit riders are willing to walk (Ewing, 1999). Therefore, it was used to delineate between households exposed to new rail service and those less exposed to the service. 


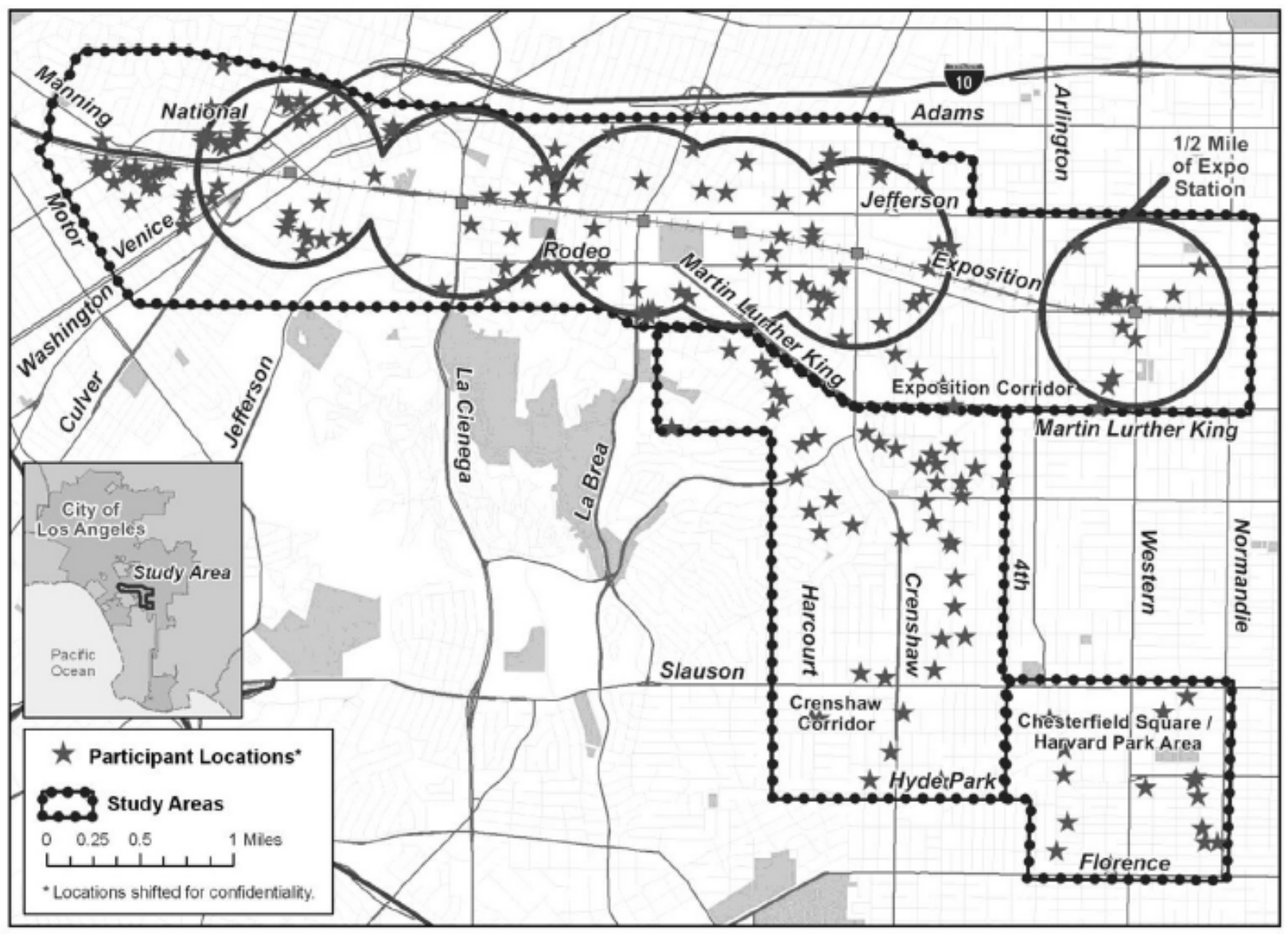

Figure 2. The Expo Line study area: Los Angeles, California, 2011-2013

\subsection{Sampling Procedure}

The present analyses use two waves of longitudinal samples from the Expo Line study. Full details of the recruitment procedures and survey instruments are described elsewhere (Houston, 2014; Spears et al., 2013). In brief, invitation letters were sent to all households $(n=27,275)$ in the study area based on addresses purchased from InfoUSA, a commercial database provider. All households with an interest in participating were selected into the study. The survey was conducted five to seven months before (Baseline, September 2011 - January 2012) and after (Follow-up, September 2012 - January 2013) the opening of the Expo Line. A total of 279 households participated in a demographic survey and a 7-day travel survey (survey sample), and each of those households was recruited to participate in the same 7-day tracking after opening of the Expo Line, and 204 households participated in after-opening data collection. The final size of the survey sample was 204 subjects who participated in both pre- and post-opening surveys. In approximately half of the before-opening households, 143 primary respondents (one per household) were recruited for participating in a more detailed survey involving accelerometer and GPS devices (mobile sample). The mobile sample participants were instructed to wear the accelerometer device on the right hip on a nylon belt around the waist during waking hours for seven days. The participants were also instructed to take off accelerometer device when engaging in rigorous athletic 
activities, such as swimming practice or a soccer match. A project staff member met with each participant to provide training on the use of the equipment, to ensure compliance with study procedures, and to provide a gift card ( $\$ 30$ for the baseline; $\$ 75$ for the follow-up) as an incentive for completing the survey. After going through a set of filtering processes which are detailed in the next section, the total size of the mobile sample came down to 73 subjects who participated in both pre- and post-opening surveys.

Our response rate for the survey sample was $1 \%$. This response rate is comparable to the response rate of 1.4\% in the 2010-2012 California Household Travel Survey (Los Angeles and Ventura Counties) and that of $0.4 \%$ in a county-wide survey that we conducted for an unrelated study of travel behavior (Houston et al., 2015, p. 10). A comparison of the households in the final sample to the households invited to participate in the study indicated that response rates did not vary greatly by household and demographic characteristics (Houston et al., 2015, p. 11). Study methods were approved by the Institutional Review Board at the University of California, Irvine.

\subsection{Measures}

Socio-demographic data. Participants completed baseline and follow-up questionnaires regarding demographic characteristics, including household income and employment status. For the regression analysis, the household income variable was converted into a dichotomous measure, 1 denoting household income below $\$ 35,000$ and 0 otherwise. The education attainment measure was dropped in the regression analysis because of multicollinearity with the household income measure. The regression results remained the same when the household income variable was replaced with the education variable.

Travel survey data. Participants completed a 7-day trip and vehicle odometer log. All household members over 12 years of age were instructed to carry the travel log, and record their trip counts for each of the following modes: private vehicle as a driver, private vehicle as a passenger, motor-cycle/scooter, bus, train, bicycle and walking. This travel survey was used to identify participants' transit usage and the frequency of trips by bus and train. A dummy variable was created to indicate whether participants increased the number of bus/train trips from pre- to post-opening surveys. The survey was also used to identify participants' frequency of walking and bicycling. Due to low frequency of bicycling trips, we used the total number of walking trips reported by the study participants as a subjective measure of active travel.

Physical activity data. Participants' physical activity was measured using GT1M accelerometers (ActiGraph, Fort Walton Beach FL, 2005). The accelerometer provides objective estimates of moderateintensity physical activities such as light or brisk walking (Sirard et al., 2000). The accelerometer collected minute-by-minute activity counts that were translated into minutes spent on different physical activity levels of light, moderate, hard, and very hard activity based on cutpoints derived from previous research (Freedson et al., 1998).

A common data reduction procedure was used to clean the accelerometer data (Matthews et al., 2012; Troiano et al., 2008). First, accelerometer "nonwear" time was defined as hours when the device was not worn, and was determined as having more than 60 minutes of consecutive zeroes for vertical acceleration, with allowance of up to 2 minutes of nonzero readings within the 60 minutes. Accelerometer "wear" time 
was defined as hours when participants were awake and wore the device. The "wear" time was determined by subtracting the "nonwear" time from $24 \mathrm{~h}$. A valid day was then determined as having 10 or more hours of accelerometer "wear" time. Participants with at least three valid days were selected into the final sample, and average moderate-and-vigorous physical activity (MVPA) minutes were calculated by combining minutes spent on moderate, hard, and very hard activities. We used the accelerometerbased MVPA minutes as an objective measure of active travel.

\subsection{Statistical analysis}

Demographics and active travel outcomes (self-reported walking and accelerometer-based physical activity) were compared between treatment and control groups using the $t$-test, and fisher test was used for categorical data. The longitudinal analysis was performed using an ANCOVA (analysis of covariance) framework, wherein the dependent variable was regressed on past behavior, the treatment condition (proximity to transit), and an interaction between the past behavior and the treatment condition. The form of the regression is shown in Equation (1).

$$
Y_{2, i}=\beta_{0}+\beta_{1} Y_{1, i}+\beta_{2} T_{i}+\beta_{3}\left(Y_{1, i} \times T_{i}\right)+X_{i}^{\prime} \gamma+\varepsilon_{i, t}
$$

$Y_{2, i}$ is an active travel outcome for individual $i$ at Time 2 (follow-up or "after opening" survey); $Y_{1, i}$ is an active travel outcome for individual $i$ at Time 1 (baseline or "before opening" survey); $T_{i}$ is the treatment condition dummy variable, equal to 1 for individuals living within $1 / 2$ mile of an Expo Line light rail and 0 for the control group living farther than $1 / 2$ mile from a station; $X_{i}{ }^{\prime}$ represents the set of covariates, including transit usage and demographics; $\varepsilon_{i, t}$ is the error term.

The interaction term $Y_{1 t} \times T_{i}$ was included to examine the moderating effect of past behavior on the relationship between new light rail transit and active travel in Time 2 (after opening). Other covariates included in the model were transit usage variables and general demographic variables which were typically hypothesized to influence active travel, such as age, gender, income, and employment status. Accelerometer data from the mobile sample were fitted using a linear regression model, and the walk trip data from the survey sample were estimated using Poisson and negative binomial regression models as those models are better suited to characterize count data. All analyses were performed using R version 3.1 and Stata version 13 (R Development Core Team, 2014; StataCorp, 2013).

\section{Results}

\subsection{Sample characteristics}

Table 1 shows the descriptive statistics of the mobile and survey samples. Roughly two thirds of the sample is female ( $66 \%$ in the mobile sample; $74 \%$ in the survey sample), and average age is 52 ( $\mathrm{SD}=14$ ) for the mobile sample and $50(\mathrm{SD}=14)$ for the survey sample. About half of the sample is AfricanAmerican (55\% in the mobile sample; $49 \%$ in the survey sample), reflecting the predominantly non-white population in the south Los Angeles neighborhood. Compared to the control subjects' characteristics, treatment subjects are slightly younger ( $51 \mathrm{vs} 53$ ) in the mobile sample, but there is virtually no difference 
in average age among the survey sample. Treatment subjects are more likely to have a graduate degree than control subjects ( $26 \%$ vs $12 \%$ ) in the mobile sample, but the proportion of graduate degree holders is the same across experimental and control groups in the survey sample. The proportion of households with income above $\$ 75,000$ is almost the same in the treatment group and control group. The treatment group has a slightly more employed primary respondents compared to the control group (59\% vs $56 \%$ in the mobile sample; $63 \%$ vs $61 \%$ in the survey sample). However, none of these differences between treatment group and control group are statistically significant, implying that the two groups are similar in terms of demographic characteristics.

The treatment subjects had lower train/bus usage at baseline compared to the control subjects, but treatment subjects' transit usage increased at follow-up. The treatment subjects spent more minutes on daily MVPA than the control subjects at baseline ( 23 minutes vs. 20 minutes), but the difference was not statistically significant. The treatment group significantly increased train trips from baseline to follow-up $(+1.14$ in the survey sample, $p<0.01 ;+0.23$ in the mobile sample, $p=0.02)$. The uptake of train trips at follow-up is expected because the new Expo Line is the only train service that is reasonably close to the study participants. The daily mean physical activity levels decreased but daily mean walk trips increased from baseline to follow-up, but these changes were not statistically significant, partly due to small magnitude of changes. 
Table 1. Descriptive statistics of study participants

\begin{tabular}{|c|c|c|c|c|c|c|c|c|}
\hline & \multicolumn{4}{|c|}{ Survey Sample $(N=204)$} & \multicolumn{4}{|c|}{ Mobile Sample $(N=73)$} \\
\hline & \multicolumn{2}{|c|}{ Time 1 (Baseline) } & \multicolumn{2}{|c|}{ Time 2 (Follow-up) } & \multicolumn{2}{|c|}{ Time 1 (Baseline) } & \multicolumn{2}{|c|}{ Time 2 (Follow-up) } \\
\hline & $\begin{array}{l}\text { Treatment } \\
(N=101)\end{array}$ & $\begin{array}{l}\text { Control } \\
(N=103)\end{array}$ & $\begin{array}{c}\text { Treatment } \\
(N=101)\end{array}$ & $\begin{array}{l}\text { Control } \\
(N=103)\end{array}$ & $\begin{array}{c}\text { Treatment } \\
(N=32)\end{array}$ & $\begin{array}{l}\text { Control } \\
(N=41)\end{array}$ & $\begin{array}{c}\text { Treatment } \\
(N=32)\end{array}$ & $\begin{array}{l}\text { Control } \\
(N=41)\end{array}$ \\
\hline & $\begin{array}{c}\text { Mean (SD) } \\
\text { or \% }\end{array}$ & $\begin{array}{c}\text { Mean (SD) } \\
\text { or } \%\end{array}$ & $\begin{array}{c}\text { Mean (SD) } \\
\text { or \% }\end{array}$ & $\begin{array}{c}\text { Mean (SD) } \\
\text { or \% }\end{array}$ & $\begin{array}{c}\text { Mean (SD) } \\
\text { or } \%\end{array}$ & $\begin{array}{c}\text { Mean (SD) } \\
\text { or } \%\end{array}$ & $\begin{array}{c}\text { Mean (SD) } \\
\text { or } \%\end{array}$ & $\begin{array}{c}\text { Mean (SD) } \\
\text { or \% }\end{array}$ \\
\hline Age & $\begin{array}{r}49.68 \\
(14.49)\end{array}$ & $\begin{array}{r}49.67 \\
(14.37)\end{array}$ & $\begin{array}{r}49.68 \\
(14.49)\end{array}$ & $\begin{array}{r}49.67 \\
(14.37)\end{array}$ & $\begin{array}{r}51.38 \\
(14.39)\end{array}$ & $\begin{array}{r}53.20 \\
(13.44)\end{array}$ & $\begin{array}{r}51.38 \\
(14.39)\end{array}$ & $\begin{array}{r}53.20 \\
(13.44)\end{array}$ \\
\hline \multicolumn{9}{|l|}{$\operatorname{Sex}(\%)$} \\
\hline Female & 79 & 70 & 79 & 70 & 72 & 61 & 72 & 61 \\
\hline Male & 21 & 30 & 21 & 30 & 28 & 39 & 28 & 39 \\
\hline \multicolumn{9}{|l|}{ Race $(\%)$} \\
\hline White & 27 & 28 & 27 & 28 & 28 & 29 & 28 & 29 \\
\hline Black & 45 & 53 & 45 & 53 & 53 & 56 & 53 & 56 \\
\hline Asian & 13 & 11 & 13 & 11 & 9 & 2 & 9 & 2 \\
\hline Hispanic & 9 & 5 & 9 & 5 & 6 & 7 & 6 & 7 \\
\hline Other & 6 & 3 & 6 & 3 & 3 & 5 & 3 & 5 \\
\hline \multicolumn{9}{|l|}{ Education (\%) } \\
\hline$<12$ th grade & 7 & 4 & 7 & 4 & 6 & 5 & 6 & 5 \\
\hline High school & 0 & 6 & 0 & 6 & 0 & 7 & 0 & 7 \\
\hline Some college & 27 & 23 & 27 & 23 & 26 & 29 & 26 & 29 \\
\hline Associate & 16 & 10 & 16 & 10 & 16 & 12 & 16 & 12 \\
\hline Bachelor & 26 & 34 & 26 & 34 & 26 & 34 & 26 & 34 \\
\hline Post graduate & 24 & 24 & 24 & 24 & 26 & 12 & 26 & 12 \\
\hline \multicolumn{9}{|l|}{ Household Income (\%) } \\
\hline$<15 \mathrm{k}$ & 17 & 15 & 17 & 15 & 16 & 15 & 16 & 15 \\
\hline $15-35 \mathrm{~K}$ & 26 & 25 & 26 & 25 & 31 & 29 & 31 & 29 \\
\hline $35-55 \mathrm{~K}$ & 20 & 19 & 20 & 19 & 9 & 10 & 9 & 10 \\
\hline $55-75 \mathrm{~K}$ & 12 & 18 & 12 & 18 & 9 & 15 & 9 & 15 \\
\hline $75-100 \mathrm{~K}$ & 12 & 11 & 12 & 11 & 19 & 15 & 19 & 15 \\
\hline$>100 \mathrm{~K}$ & 12 & 14 & 12 & 14 & 16 & 17 & 16 & 17 \\
\hline \multicolumn{9}{|l|}{ Employment status (\%) } \\
\hline Not employed & 37 & 39 & 37 & 39 & 41 & 44 & 41 & 44 \\
\hline Employed & 63 & 61 & 63 & 61 & 59 & 56 & 59 & 56 \\
\hline Average daily train trips & $\begin{array}{r}0.36 \\
(1.76)\end{array}$ & $\begin{array}{r}0.20 \\
(0.81)\end{array}$ & $\begin{array}{r}1.50 \\
(3.39)\end{array}$ & $\begin{array}{r}0.23 \\
(1.24)\end{array}$ & $\begin{array}{r}0.01 \\
(0.07)\end{array}$ & $\begin{array}{r}0.05 \\
(0.15)\end{array}$ & $\begin{array}{r}0.24 \\
(0.58)\end{array}$ & $\begin{array}{r}0.01 \\
(0.07)\end{array}$ \\
\hline Average daily bus trips & $\begin{array}{r}3.13 \\
(6.34)\end{array}$ & $\begin{array}{r}2.23 \\
(5.76)\end{array}$ & $\begin{array}{r}2.77 \\
(6.40)\end{array}$ & $\begin{array}{r}1.83 \\
(4.79)\end{array}$ & $\begin{array}{r}0.32 \\
(0.62)\end{array}$ & $\begin{array}{r}0.43 \\
(0.95)\end{array}$ & $\begin{array}{r}0.46 \\
(0.98)\end{array}$ & $\begin{array}{r}0.24 \\
(0.54)\end{array}$ \\
\hline $\begin{array}{l}\text { Average daily MVPA } \\
\text { minutes }\end{array}$ & & & & & $\begin{array}{r}23.09 \\
(17.49)\end{array}$ & $\begin{array}{r}19.81 \\
(18.01)\end{array}$ & $\begin{array}{r}21.52 \\
(16.24)\end{array}$ & $\begin{array}{r}18.56 \\
(17.02)\end{array}$ \\
\hline Average daily walk trips & $\begin{array}{r}7.00 \\
(7.19)\end{array}$ & $\begin{array}{r}4.66 \\
(6.06)\end{array}$ & $\begin{array}{r}8.56 \\
(11.29)\end{array}$ & $\begin{array}{r}5.49 \\
(7.54)\end{array}$ & & & & \\
\hline
\end{tabular}

Note. Numbers may not sum to $100 \%$ due to rounding. Significance of difference was determined by $t$-tests for continuous variables and Fisher tests for categorical variables.

$* p<0.05,{ }^{* *} p<0.01, * * * p<0.001$

\subsection{Walk trip model results}

Table 2 shows the results of Poisson and negative binomial models using total walk trip counts obtained from the survey sample $(n=204)$. In the Poisson model (Table 2), the treatment variable was positively associated with the total walk trip counts $(\beta=0.27, p=0.001)$. Baseline walk trips were also positively associated with walk trip counts at follow-up $(\beta=0.05, p<0.001)$. The interaction term between treatment and baseline walk trips was negatively associated with total walk trips $(\beta=-0.02, p=0.008)$. This 
suggests that the positive relationship between transit and walk trips is moderated by the subjects' past walking conditions. The coefficients on increased train and bus usage ( 1 if the study subject increased self-reported train or bus trips from the pre- to the post-opening survey) were positive and highly statistically significant ( $\beta=0.54, p<0.001$ and $\beta=0.51, p<0.001$ for train and bus, respectively), indicating a high correlation between transit usage and walking trip. Note that the treatment effect of transit proximity on walking trip was still evident and strong after controlling for the transit usage. The negative binomial regression model results were more or less the same as that of the Poisson model, except that the magnitudes of the key variables (treatment, baseline walk trips, and the interaction term) were larger, and none of the demographic controls were statistically significant. However, the negative binomial model appears to give more reliable results as it has substantially better goodness-of-fit measures (AIC/BIC) than the Poisson model. On net, the walk trip models confirm our hypothesis that the transit had a positive impact on walking behavior of residents in the treatment group, but that impact appears be moderated by previous walking behavior of study participants.

Table 2. Poisson and negative binomial models of total walk trip counts

\begin{tabular}{|c|c|c|c|c|c|c|}
\hline \multirow{2}{*}{ Variable } & \multicolumn{3}{|c|}{ Poisson Model } & \multicolumn{3}{|c|}{ Negative Binomial Model } \\
\hline & $\beta$ & $p$ & & $\beta$ & $p$ & \\
\hline Treatment $($ within $1 / 2$ mile $=1)$ & 0.27 & 0.001 & *** & 0.52 & 0.021 & ** \\
\hline Baseline walk trips & 0.05 & $<0.001$ & *** & 0.09 & $<0.001$ & *** \\
\hline Treatment $\times$ Baseline walk trips & -0.02 & 0.008 & $* * *$ & -0.05 & 0.019 & $* *$ \\
\hline Train usage (increased trips $=1$ ) & 0.54 & $<0.001$ & ${ }^{* * *}$ & 0.51 & 0.026 & $* *$ \\
\hline Bus usage (increased trips $=1$ ) & 0.51 & $<0.001$ & *** & 0.70 & 0.001 & $* * *$ \\
\hline Age $(20-84$ y) & 0.00 & 0.189 & & 0.00 & 0.914 & \\
\hline Gender $($ male $=1)$ & 0.12 & 0.049 & ** & 0.07 & 0.724 & \\
\hline Household income (below $35 \mathrm{k}=1$ ) & 0.35 & $<0.001$ & $* * *$ & 0.28 & 0.135 & \\
\hline Employment $($ employed $=1)$ & 0.27 & $<0.001$ & *** & 0.08 & 0.669 & \\
\hline$N$ & & 200 & & & 200 & \\
\hline Log-likelihood & & -875.6 & & & -551.2 & \\
\hline $\mathrm{AIC}$ & & 9.2 & & & 5.6 & \\
\hline $\mathrm{BIC}$ & & 814.3 & & & 101.1 & \\
\hline
\end{tabular}

Note. The dependent variable is a total walk trip count in Time 2 . Four subjects with partial data were excluded from all models $* \mathrm{p}<0.10, * * \mathrm{p}<0.05, * * * \mathrm{p}<0.01$

\subsection{Physical activity model results}

Table 3 shows the results for the accelerometer-based physical activity data. The physical activity data were obtained from a smaller but more objective accelerometer data, allowing us to corroborate our result with a more precise measure of active travel behavior. In Model 1, the baseline moderate-andvigorous physical activity (MVPA) was positively associated with MVPA at follow-up $(\beta=0.47, p<$ $0.001)$. The coefficient on the treatment variable was positive but not statistically significant $(\beta=1.89$, 
$p=0.547$ ), meaning that the new light rail had no direct effect on physical activity outcomes in Model 1 . Similar to the walk trip model results presented in Table 2, Model 2 adds the interaction term $Y_{1 t} \times$ $T_{i}$. Compared to Model 1, both the effect size and the statistical significance of the treatment effect increase in Model 2. Being in the treatment group was associated with more minutes of daily MVPA at follow-up ( $\beta=9.29, p=0.066$ ) in Model 2. However, this positive treatment effect was attenuated by baseline physical activity levels, as indicated by the negative sign of the interaction term between treatment and baseline MVPA $(\beta=-0.34, p=0.063)$. Model 3 shows the effect of increasing train or bus usage, by adding dummy variables $=1$ if the study subject increased self-reported train or bus trips from the pre- to the post-opening survey. The coefficient on increased train usage was positive but not statistically significant $(\beta=3.14, p=0.516)$. However, the coefficient on increased bus usage was positive and statistically significant $(\beta=14.63, p<0.001)$. The coefficients (magnitude and significance) on the treatment dummy variable and the interaction term $Y_{1 t} \times T_{i}$ are similar in Model 3 and Model 2. Other covariates followed the expected signs and patterns as previous studies (Troiano et al., 2008). Overall, the physical activity model results suggest that there is a positive relationship between treatment (living close to the new transit station) and physical activity, but the baseline physical activity levels moderated this relationship.

Table 3. Linear regression models of moderate-and-vigorous physical activity

\begin{tabular}{|c|c|c|c|c|c|c|c|c|c|}
\hline \multirow{2}{*}{ Variable } & \multicolumn{3}{|c|}{ Model 1} & \multicolumn{3}{|c|}{ Model 2} & \multicolumn{3}{|c|}{ Model 3} \\
\hline & $\beta$ & $p$ & & $\beta$ & $p$ & & $\beta$ & $p$ & \\
\hline Treatment $($ within $1 / 2$ mile $=1)$ & 1.89 & 0.547 & & 9.29 & 0.066 & $*$ & 7.90 & 0.088 & $*$ \\
\hline Baseline MVPA & 0.47 & $<0.001$ & *** & 0.60 & $<0.001$ & ${ }^{* * *}$ & 0.60 & $<0.001$ & *** \\
\hline Treatment $\times$ Baseline MVPA & & & & -0.34 & 0.063 & * & -0.37 & 0.026 & ** \\
\hline Train usage (increased trips $=1$ ) & & & & & & & 3.14 & 0.516 & \\
\hline Bus usage (increased trips $=1$ ) & & & & & & & 14.63 & $<0.001$ & *** \\
\hline Age $(20-84$ y) & -0.19 & 0.126 & & -0.20 & 0.102 & & -0.24 & 0.038 & $* *$ \\
\hline Gender $($ male $=1)$ & 8.91 & 0.010 & *** & 10.06 & 0.004 & $* * *$ & 8.51 & 0.009 & *** \\
\hline Household income (below $35 \mathrm{k}=1$ ) & 1.52 & 0.636 & & 2.42 & 0.450 & & -0.42 & 0.889 & \\
\hline Employment $($ employed $=1)$ & 3.75 & 0.267 & & 3.83 & 0.249 & & 3.28 & 0.278 & \\
\hline$N$ & & 73 & & & 73 & & & 72 & \\
\hline $\mathrm{R}^{2}$ & & 0.44 & & & 0.47 & & & 0.59 & \\
\hline Adjusted $\mathrm{R}^{2}$ & & 0.38 & & & 0.41 & & & 0.53 & \\
\hline
\end{tabular}

Note. The dependent variable is daily average MVPA minutes in Time 2. One subject with partial data was excluded in Model 3.

$* \mathrm{p}<0.10, * * \mathrm{p}<0.05, * * * \mathrm{p}<0.01$

To further illustrate the moderating effects of baseline physical activity, we computed the marginal effect of the treatment on moderate-and-vigorous physical activity (MVPA) at follow-up and plotted regression lines using Model 3 while holding age at the mean and other covariates (binary variables) at zero. Figure 3 shows the predicted MVPA at follow-up as a function of baseline MVPA for the treatment group (solid line) and the control group (dotted line). The crossing of the two regression lines illustrates 
that the rail treatment effect changes with the subjects' physical activity levels at baseline. Compared to the control subjects, the treatment subjects below the $46^{\text {th }}$ sample percentile of baseline MVPA had a positive rail treatment effect whereas those above the $46^{\text {th }}$ percentile had a negative treatment effect. This graph demonstrates that the relationship between transit and physical activity is moderated by participant's baseline physical activity levels.

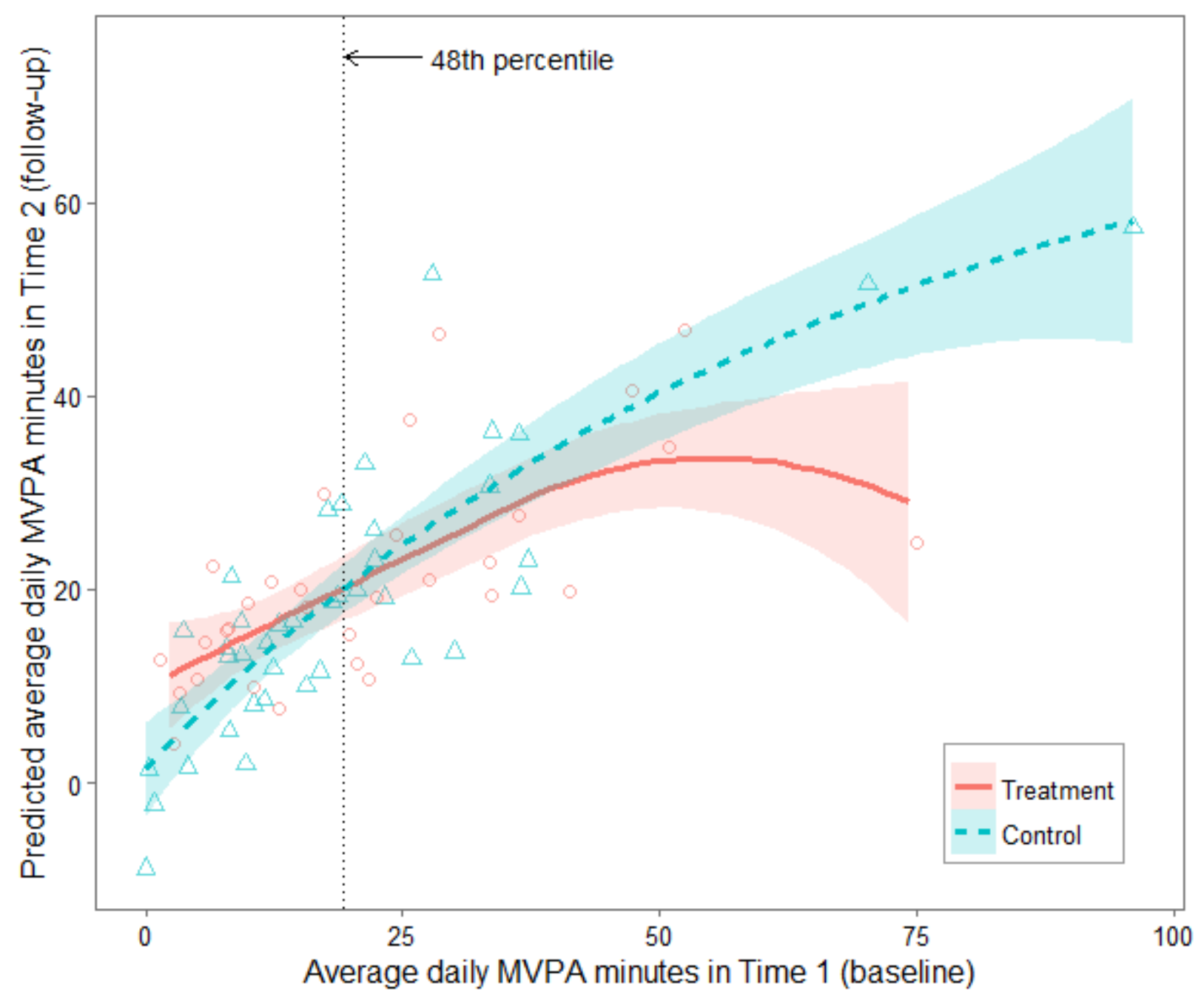

Figure 3. Moderating effect of past behavior on treatment

Note. The solid line and dotted line each represent the regression line for control group and treatment group based on Model 3 in Table 2, holding age at the mean and other covariates at zero. The shaded area around each regression line represents the $95 \%$ confidence interval.

\subsection{Robustness checks}

Because of the small sample size for the physical activity model (Table 3), we further examined the possibility that the results are driven by extreme values in the data set. Four additional models were developed with different outlier removal criteria (Figure 4). The outlier models 1 and 2 define outliers as the absolute and relative changes in MVPA between the pre- and post-surveys based on a commonly used 
Turkey method (Turkey, 1977). Using this method, we calculated an interquartile range for the absolute change in MVPA (outlier model 1) and the changes in MVPA relative to pre-opening MVPA or postopening MVPA (outlier model 2). Then, outliers were selected based on these change scores being greater than 1.5 times interquartile range. The outlier models 3 and 4 were developed based on a comprehensive set of outlier indicators using residuals, leverage, Cook's D, DFITS, and DFBETA (Hamilton, 2012). The outlier model 3 excludes the most common outliers, and the model 4 excludes all outliers identified by the outlier indicators.

Comparison of the outlier models indicates that the effect sizes and the significance values for the key variables do not vary greatly across the different outlier criteria (Figure 4). The coefficients on the treatment variable and the interaction term are stable and significant at the 5 to $10 \%$ level across the models. The coefficient on baseline MVPA is also stable and highly significant at the $0.1 \%$ level across all the models. A comparison between the original model and the outlier models indicated that the results are robust to different outlier removal criteria, and that our model results are not driven by the potential outliers in the data set.

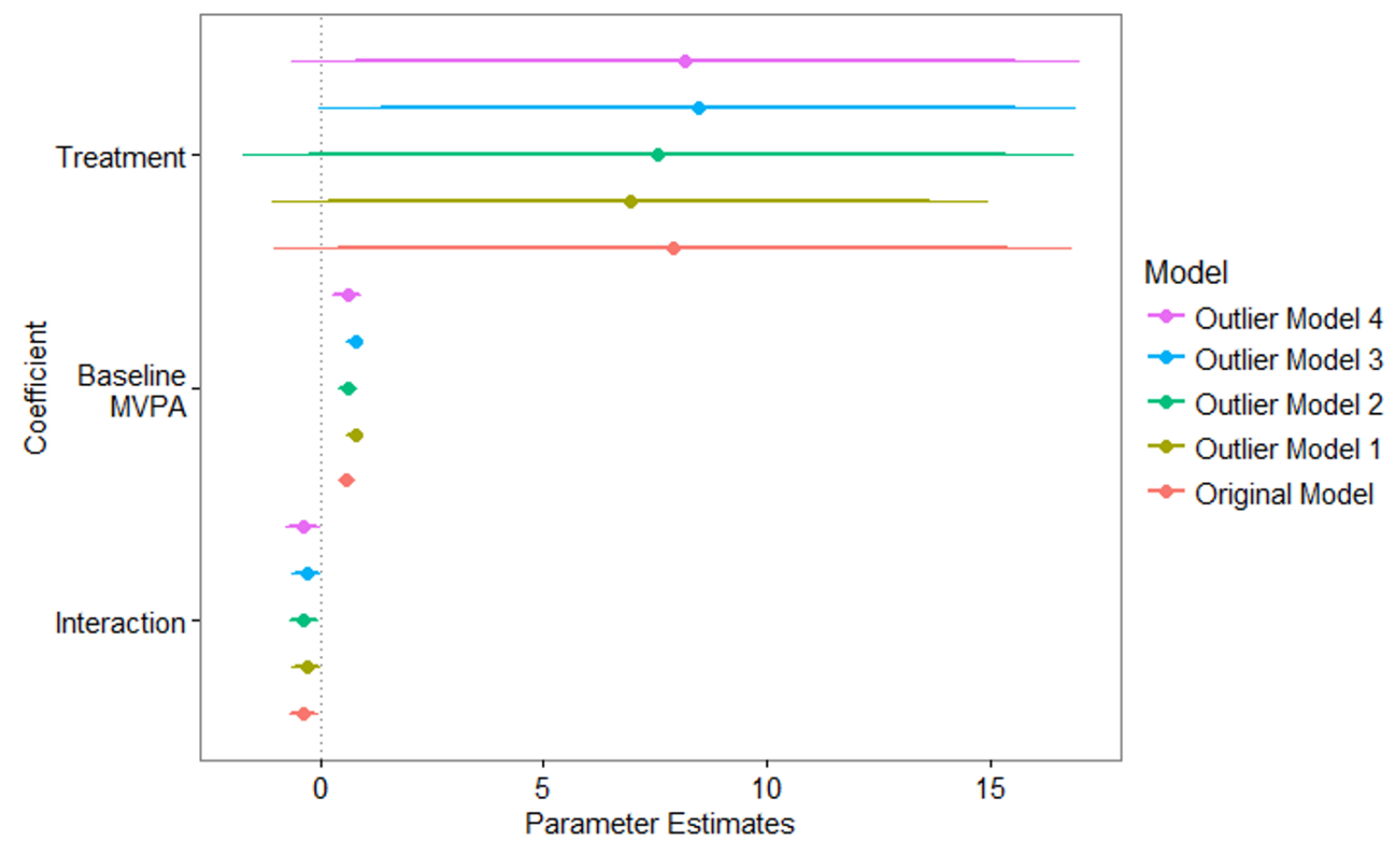

Figure 4. Comparison between the original model and the outlier models

Note. The thick line indicates $90 \% \mathrm{CI}$, and the thin line indicates $95 \% \mathrm{CI}$.

To further ensure the robustness of our models, we also checked the possibility of a 'regression toward the mean' effect. Regression to the mean can occur when a baseline measure of the outcome variable is used to predict changes over time (Bland and Altman, 1994). It is possible that in our sample subjects' physical activity levels move toward the mean over time for reasons having little to do with the treatment effect, and we want to confirm that the negative coefficient on the interaction terms in Tables 2 
and 3 is not simple regression to the mean. We developed a Monte Carlo Simulation of random treatment models to test whether the negative interaction terms reflect real interactions with the light rail treatment effect. Rather than using the treatment dummy variable ( $=1$ for subjects living within $1 / 2$ mile of an Expo Line station), we randomly assigned the treatment dummy variable to all subjects in the mobile sample. We then reran the regression in Equation (1). The treatment effect variable, being randomly assigned, should be statistically insignificant, as should the interaction term $Y_{1 t} \times T_{i}$. If the interaction term is negative and statistically significant in this random treatment effect model, that would be evidence that the interaction term reflects regression to the mean. On the other hand, if the interaction term is not significantly different from zero, that increases our confidence that the negative interaction terms in Tables 2 and 3 indicate real interactions between baseline physical activity and the light rail treatment, not regression to the mean. We ran a set of regression models with the randomly assigned treatment variable using the same functional form and specifications as the original models (the Negative Binomial Model from Table 2 and Model 3 from Table 2). These models were replicated 1,000 times with different random assignment of the treatment variable.

Figure 5 shows the results of the Monte Carlo simulation of the random treatment models. As expected, the mean parameter estimates for the baseline MVPA and baseline walk trips are similar to what was observed in the original models. However, the parameter estimates for the random treatment variable and the interaction term, $Y_{1 t} \times T_{i}$ where $T_{i}$ is the randomly assigned treatment variable, were both approximately symmetrically distributed with zero mean. This suggests that there is no treatment effect with the random treatment models, and we conclude that the interaction term in our original models does not reflect regression to the mean. 


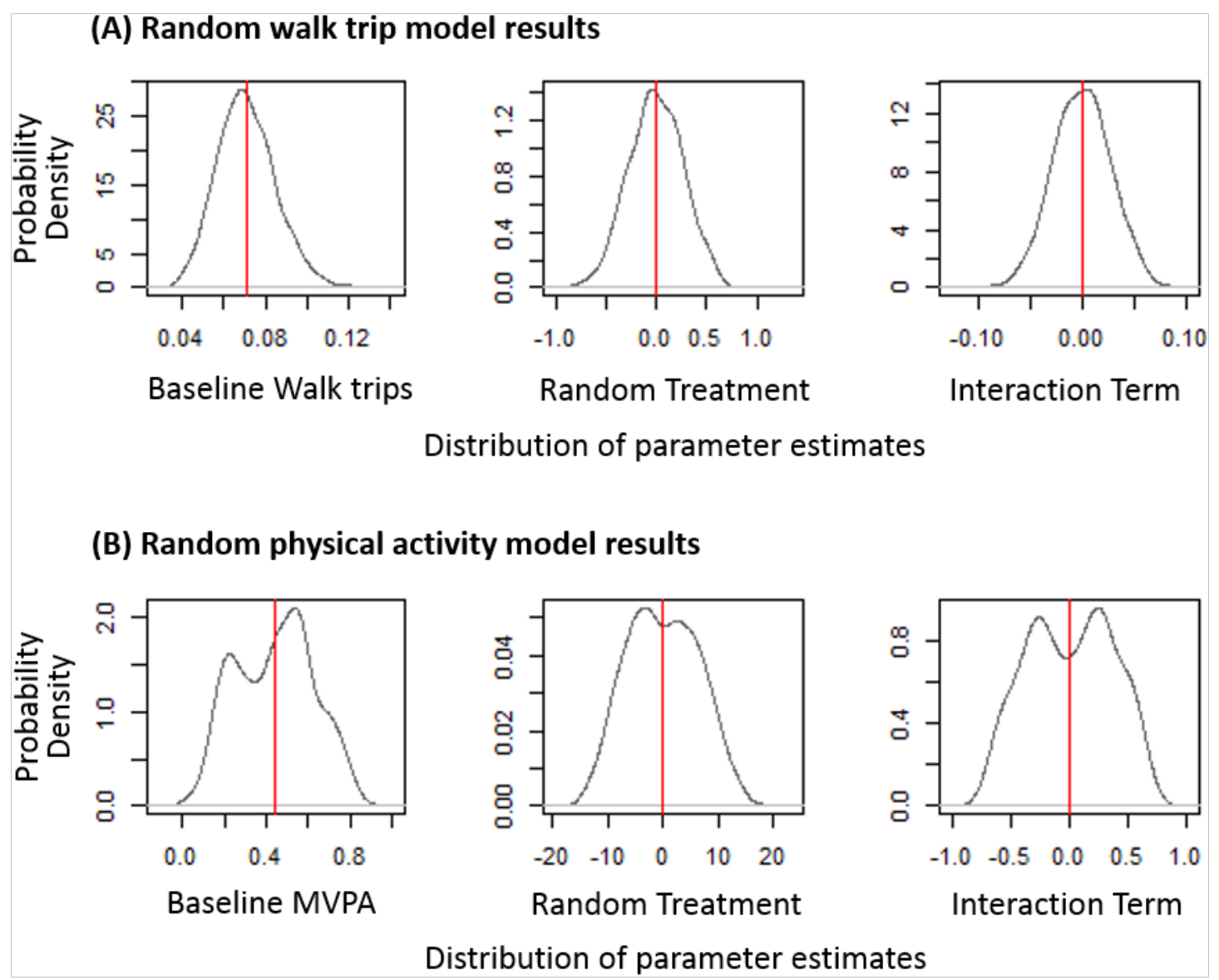

Figure 5. Monte Carlo simulation of the random treatment models

Note. The red vertical lines indicate the mean values. The means and SDs (in parenthesis) are $0.45(0.19), 0.16(6.39)$, and $0.01(0.37)$ from left to right in the first row; and $0.07(0.01),-0.01(0.28)$, and $0(0.03)$ from left to right in the second row.

\section{Discussion}

This study is one of the few quasi-experimental, longitudinal studies on the relationship between transit and active travel behavior. The unique research design provided a rare opportunity to compare the same households before and after a major improvement in transportation infrastructure, and we were able to employ both objective (accelerometer) and subjective (travel surveys) measures of active travel behavior. One of the major findings from this study is that there was no significant light rail treatment effect in a simple model that does not control for the moderating effect of baseline walking and physical activity. This is consistent with the two previous longitudinal studies in that exposure to the new light rail transit did not directly predict physical activity and walking, and even resulted in a declining trend of total physical activity (Brown and Werner, 2007; MacDonald et al., 2010). In fact, declining physical activity is common in other longitudinal studies of youth and older adults. Evenson et al (2010) reported a declining physical activity trend over a 2-year period among a cohort of adolescent girls, and the transport and neighborhood measures were not associated with changes in physical activity. This contradicts their 
own findings from an earlier cross-sectional study which showed positive associations between the transport and neighborhood measures and physical activity (Evenson, 2006; Evenson et al., 2010). For older adults, Bijnen et al (1998) found age-related reductions in total physical activity in a cohort sample of elderly Dutch men over a 10-year period. Visser et al (2002) also found that total physical activity of older adults (both men and women) in Amsterdam declined over a 3-year study period.

Although we found little association between transit proximity and active travel in the simple model, the subsequent ANCOVA models supported our second hypothesis about the moderating role of past behavior on the light rail treatment effect. Both walking and physical activity levels at baseline moderated the relationship between transit and walking and physical activity at follow-up, and after controlling for that moderating effect, the new light rail transit line was associated with increased walking and physical activity for the least active study subjects. Similar results have been found in other research. In a recent study of a recess-based intervention program targeted to school children (Saint-Maurice et al., 2014), children had differential effects when exposed to various interventions, and baseline activity level was the key moderator. They observed that low active students were more responsive to changes in the environment of school recess programming, and the nature of the intervention influenced the effectiveness of the intervention. Thøgersen (2006) also found that past behavior was a strong predictor of current behavior, over and above the psychological and socioeconomic variables, including attitude, perceived control/opportunities to use public transit, and car ownership. He cautiously interprets this result as providing evidence that when behavior is performed frequently in a stable manner, habitual processes are partly responsible for the effect of past on current behavior. Gardner (2009) observed that habits, which correlate strongly with past behavior, moderated the intention to use a car or a bicycle. He noted that among habitual travelers, their behaviors were mainly influenced by habitual tendencies, not intentions. However, intention had a strong effect on behavior among less habitual travelers, implying that policy interventions that are designed to affect intentions and behavior change may have differential impacts depending on individuals' strength of past behavior and behavioral motivations. These findings resonate with our results in that the treatment subjects who were the least physically active (i.e. people with less tendency for habitual exercise) were more responsive to exposure to the new light rail transit service. This suggests that environmental interventions intended to change active travel behavior would likely to be more effective for people with previously low physical activity levels or with less tendency for habitual physical activity.

While our results reveal an important relationship between new transit investment and active travel behavior, there are several limitations to our study. First, although all households in the study area were invited to participate, and there were no differential response rates between the study households and the households recruited to participate in the study, participating households could have been more highly motivated to participate in multiple phases of data collection and to carry an accelerometer in each phase than non-respondents. Second, the small sample size and geographic focus of this study may limit the generalizability of our findings. We recommend further research using longitudinal designs in other settings to learn more about the generalizability of our findings. 


\section{Conclusion and Policy Implications}

The findings from this study provide important contributions and implications for future policy and research. First, our results indicate that environmental interventions are not straightforward, and a health impact assessment of transit investments should use an experimental approach that can account for potential moderators or confounders. The results of this study suggest that a new transit service may not necessarily promote active travel for everyone in the community, calling for caution in making a general assumption about the effects of transit investments on active travel behavior. Another key contribution of this study lies in finding the moderating effects of past behavior on the relationship between new light rail transit and active travel. Our results suggest that while transit proximity or exposure to new transit influences active travel, the impact of a new transit service would depend on past behavior. In particular, for the treatment subjects who had previously low walking and physical activity levels, living within a half-mile of a transit station was associated with an increase in walking and physical activity after the opening of the new light rail transit line. More experimental research of this kind is needed to substantiate the findings of the current study, preferably in different contexts and populations. Nonetheless, our results suggest that sedentary population may be more responsive to new transit investments, calling for more targeted approaches in transit service to encourage people to make healthy travel choices. Such approaches may include providing better transit information or adopting marketing strategies targeted at the individuals with low active travel but are more motivated to use public transit.

\section{References}

Aarts, H., Paulussen, T., Schaalma, H., 1997. Physical exercise habit: on the conceptualization and formation of habitual health behaviours. Health Educ. Res. 12, 363-374.

Ajzen, I., 1991. The Theory of Planned Behavior. Organ. Behav. Hum. Decis. Process. 50, 179-211.

Ajzen, I., 2002. Residual Effects of Past on Later Behavior: Habituation and Reasoned Action Perspectives. Personal. Soc. Psychol. Rev. 6, 107. doi:10.1207/S15327957PSPR0602

Ajzen, I., Fishbein, M., 1980. Understanding attitudes and predicting social behavior. Prentice-Hall, Englewood Cliffs, NJ.

Badland, H., Schofield, G., 2005. Transport, urban design, and physical activity: an evidence-based update. Transp. Res. Part D Transp. Environ. 10, 177-196. doi:10.1016/j.trd.2004.12.001

Bamberg, S., Ajzen, I., Schmidt, P., 2003. Choice of travel mode in the theory of planned behavior: The roles of past behavior, habit, and reasoned action. Basic Appl. Soc. Psych. 25, 175-187.

doi:10.1016/j.tranpol.2010.08.006

Bassett, D.R., Pucher, J., Buehler, R., Thompson, D.L., Crouter, S.E., 2008. Walking, cycling, and obesity rates in Europe, North America, and Australia. J. Phys. Act. Health 5, 795-814. 
Bauman, A.E., Sallis, J.F., Dzewaltowski, D. a, Owen, N., 2002. Toward a better understanding of the influences on physical activity. Am. J. Prev. Med. 23, 5-14. doi:10.1016/S0749-3797(02)00469-5

Bentler, P.M., Speckart, G., 1979. Models of Attitude-Behavior Relations. Psychol. Rev. 86, 452-464.

Besser, L., Dannenberg, A.L., 2005. Walking to public transit: steps to help meet physical activity recommendations. Am. J. Prev. Med. 29. doi:10.1016/j.ampre.2005.06.010

Bijnen, F., 1998. Age, period, and cohort effects on physical activity among elderly men during 10 years of follow-up: the Zutphen Elderly Study. Journals Gerontol. Ser. A Biol. Sci. Med. Sci. 53, 235-241.

Bland, J.M., Altman, D.G., 1994. Statistical notes: Regression towards the mean. BMJ Br. Med. J. 308, 1499. doi:10.1136/bmj.308.6942.1499

Bors, P., Dessauer, M., Bell, R., Wilkerson, R., Lee, J., Strunk, S.L., 2009. The Active Living by Design national program: community initiatives and lessons learned. Am. J. Prev. Med. 37, S313-21. doi:10.1016/j.amepre.2009.09.027

Brown, B.B., Werner, C.M., 2007. A new rail stop: tracking moderate physical activity bouts and ridership. Am. J. Prev. Med. 33, 306-9. doi:10.1016/j.amepre.2007.06.002

Brown, B.B., Werner, C.M., 2008. Before and After a New Light Rail Stop: Resident Attitudes, Travel Behavior, and Obesity. J. Am. Plan. Assoc. 75, 5-12. doi:10.1080/01944360802458013

Brownson, R.C., Boehmer, T.K., Luke, D.A., 2005. Declining rates of physical activity in the United States: What are the contributors? Annu. Rev. Public Health 26, 421-43.

Brownson, R.C., Hoehner, C.M., Day, K., Forsyth, A., Sallis, J.F., 2009. Measuring the built environment for physical activity: state of the science. Am. J. Prev. Med. 36, S99-123.e12.

Cao, X. (Jason), Handy, S.L., Mokhtarian, P.L., 2006. The Influences of the Built Environment and Residential Self-Selection on Pedestrian Behavior: Evidence from Austin, TX. Transportation (Amst). 33, 1-20.

Carlson, J.A., Sallis, J.F., Conway, T.L., Saelens, B.E., Frank, L.D., Kerr, J., Cain, K.L., King, A.C., 2012. Interactions between psychosocial and built environment factors in explaining older adults' physical activity. Prev. Med. (Baltim). 54, 68-73. doi:10.1016/j.ypmed.2011.10.004

Evenson, K., 2006. Girls' perception of physical environmental factors and transportation: reliability and association with physical activity and active transport to school. Int. J. Behav. Nutr. Phys. Act. 16, 1-16. doi:10.1186/1479-Received

Evenson, K.R., Murray, D.M., Birnbaum, A.S., Cohen, D.A., 2010. Examination of perceived neighborhood characteristics and transportation on changes in physical activity and sedentary behavior: The Trial of Activity in Adolescent Girls. Health Place 16, 977-85. doi:10.1016/j.healthplace.2010.06.002

Ewing, R., 1999. Pedestrian-and transit-friendly design: a primer for smart growth. Washington, DC. 
Frank, L.D., Sallis, J.F., Conway, T.L., Chapman, J.E., Saelens, B.E., Bachman, W., 2006. Many pathways from land use to health: associations between neighborhood walkability and active transportation, body mass index, and air quality. J. Am. Plan. Assoc. 72, 75-87.

Fredricks, A.J., Dossett, D.L., 1983. Attitude-behavior relations: A comparison of the Fishbein-Ajzen and the Bentler-Speckart models. J. Pers. Soc. Psychol. 45, 501-512. doi:10.1037/0022-3514.45.3.501

Freedson, P.S., Melanson, E., Sirard, J., 1998. Calibration of the Computer Science and Applications, Inc. accelerometer. Med. Sci. Sports Exerc. 30, 777-81.

Gardner, B., 2009. Modelling motivation and habit in stable travel mode contexts. Transp. Res. Part F Traffic Psychol. Behav. 12, 68-76. doi:10.1016/j.trf.2008.08.001

Gärling, T., Axhausen, K.W., 2003. Introduction: Habitual travel choice. Transportation (Amst). 30, 1-11. doi:10.1023/A:1021230223001

Glanz, K., Rimer, B.K., Viswanath, K., 2008. Health behavior and health education. Heal. Educ. Behav. $30,7-9$.

Hagger, M., 2001. The influence of self-efficacy and past behaviour on the physical activity intentions of young people. J. Sports Sci. 19, 711-725.

Hamilton, L., 2012. Regression diagnostics, in: Statistics with Stata: Version 12. Cengage Learning, Boston, MA, pp. 209-228.

Handy, S.L., Boarnet, M.G., Ewing, R., Killingsworth, R.E., 2002. How the built environment affects physical activity: views from urban planning. Am. J. Prev. Med. 23, 64-73.

Houston, D., 2014. Implications of the modifiable areal unit problem for assessing built environment correlates of moderate and vigorous physical activity. Appl. Geogr. 50, 40-47.

doi:10.1016/j.apgeog.2014.02.008

Houston, D., Boarnet, M., Spears, S., 2015. Final Report - Evaluating the Benefits of Light Rail Transit. Sacramento, CA.

Kerr, J., Norman, G.J., Adams, M. a, Ryan, S., Frank, L.D., Sallis, J.F., Calfas, K.J., Patrick, K., 2010. Do neighborhood environments moderate the effect of physical activity lifestyle interventions in adults? Health Place 16, 903-8. doi:10.1016/j.healthplace.2010.05.002

King, A.C., Stokols, D., Talen, E., Brassington, G.S., Killingsworth, R., 2002. Theoretical approaches to the promotion of physical activity: forging a transdisciplinary paradigm. Am. J. Prev. Med. 23, 1525.

Lachapelle, U., Frank, L.D., Saelens, B.E., Sallis, J.F., Conway, T.L., 2011. Commuting by public transit and physical activity: where you live, where you work, and how you get there. J. Phys. Act. Health 8 , S72-S82.

Lachapelle, U., Noland, R.B., 2012. Does the commute mode affect the frequency of walking behavior? The public transit link. Transp. Policy 21, 26-36. doi:10.1016/j.tranpol.2012.01.008 
Lee, I., Shiroma, E., Lobelo, F., Puska, P., 2012. Effect of physical inactivity on major noncommunicable diseases worldwide: an analysis of burden of disease and life expectancy. Lancet $6736,1-11$.

MacDonald, J.M., Stokes, R.J., Cohen, D. a, Kofner, A., Ridgeway, G.K., 2010. The effect of light rail transit on body mass index and physical activity. Am. J. Prev. Med. 39, 105-112. doi:10.1016/j.amepre.2010.03.016

Matthews, C.E., Hagströmer, M., Pober, D.M., Bowles, H.R., 2012. Best practices for using physical activity monitors in population-based research. Med. Sci. Sports Exerc. 44, S68-76. doi:10.1249/MSS.0b013e3182399e5b

McCormack, G.R., Giles-Corti, B., Bulsara, M., 2008. The relationship between destination proximity, destination mix and physical activity behaviors. Prev. Med. (Baltim). 46, 33-40. doi:10.1016/j.ypmed.2007.01.013

McNeill, L.H., Kreuter, M.W., Subramanian, S. V., 2006. Social Environment and Physical activity: A review of concepts and evidence. Soc. Sci. Med. 63, 1011-1022. doi:10.1016/j.socscimed.2006.03.012

Morency, C., Trépanier, M., Demers, M., 2011. Walking to transit: An unexpected source of physical activity. Transp. Policy 18, 800-806. doi:10.1016/j.tranpol.2011.03.010

Norman, P., Conner, M., Bell, R., 2000. The Theory of Planned Behaviour and exercise: Evidence for the moderating role of past behaviour. Br. J. Health Psychol. 5, 249-261. doi:10.1348/135910700168892

Ouellette, J., Wood, W., 1998. Habit and intention in everyday life: the multiple processes by which past behavior predicts future behavior. Psychol. Bull. 124, 54-74.

Pickett, K.E., Pearl, M., 2001. Multilevel analyses of neighbourhood socioeconomic context and health outcomes: a critical review. J. Epidemiol. Community Health 55, 111-22.

R Development Core Team, 2014. A language and environment for statistical computing.

Rissel, C., Curac, N., Greenaway, M., Bauman, A., 2012. Physical activity associated with public transport use--a review and modelling of potential benefits. Int. J. Environ. Res. Public Health 9, 2454-78. doi:10.3390/ijerph9072454

Saelens, B.E., Sallis, J.F., Frank, L.D., 2003. Environmental correlates of walking and cycling: findings from the transportation, urban design, and planning literatures. Ann. Behav. Med. 25, 80-91.

Saint-Maurice, P.F., Welk, G.J., Russell, D.W., Huberty, J., 2014. Moderating influences of baseline activity levels in school physical activity programming for children: the Ready for Recess project. BMC Public Health 14, 103. doi:10.1186/1471-2458-14-103

Sallis, J.F., Cervero, R.B., Ascher, W., Henderson, K. a K.A., Kraft, M.K.K., Kerr, J., 2006. An ecological approach to creating active living communities. Annu. Rev. Public Health 27, 297-322. doi:10.1146/annurev.publhealth.27.021405.102100 
Sallis, J.F., Frank, L.D., Saelens, B.E., Kraft, M.K., 2004. Active transportation and physical activity: opportunities for collaboration on transportation and public health research. Transp. Res. A Policy Pract. 38, 249-268.

Sirard, J., Melanson, E., Li, L., Freedson, P., 2000. Field evaluation of the Computer Science and Applications, Inc. physical activity monitor. Med. Sci. Sport. Exerc. 7164, 695-700.

Spears, S., Houston, D., Boarnet, M.G., 2013. Illuminating the unseen in transit use: A framework for examining the effect of attitudes and perceptions on travel behavior. Transp. Res. Part A Policy Pract. 58, 40-53. doi:10.1016/j.tra.2013.10.011

StataCorp, 2013. Stata Statistical Software: Release 13.

Stokes, R.J., MacDonald, J., Ridgeway, G., 2008. Estimating the effects of light rail transit on health care costs. Health Place 14, 45-58. doi:10.1016/j.healthplace.2007.04.002

Thøgersen, J., 2006. Understanding repetitive travel mode choices in a stable context: A panel study approach. Transp. Res. Part A Policy Pract. 40, 621-638. doi:10.1016/j.tra.2005.11.004

Timperio, A., Ball, K., Salmon, J., Roberts, R., Giles-Corti, B., Simmons, D., Baur, L. a, Crawford, D., 2006. Personal, family, social, and environmental correlates of active commuting to school. Am. J. Prev. Med. 30, 45-51. doi:10.1016/j.amepre.2005.08.047

Troiano, R.P., Berrigan, D., Dodd, K.W., Mâsse, L.C., Tilert, T., McDowell, M., 2008. Physical activity in the United States measured by accelerometer. Med. Sci. Sports Exerc. 40, 181-8. doi:10.1249/mss.0b013e31815a51b3

Turkey, J.W., 1977. Exploratory data analysis. Addison-Wesley, Boston, MA.

US DOT, 2014. Statewide transportation planning for healthy communities. Washington, DC.

Verplanken, B., Melkevik, O., 2008. Predicting habit: The case of physical exercise. Psychol. Sport Exerc. 9, 15-26. doi:10.1016/j.psychsport.2007.01.002

Visser, M., Pluijm, S., 2002. Physical activity as a determinant of change in mobility performance: The Longitudinal Aging Study Amsterdam. J. Am. Geriatr. Soc. 50, 1774-1781.

WHO, 2009. Global health risks: mortality and burden of disease attributable to selected major risks. World Health Organization, Geneva.

Yordy, G., Lent, R., 1993. Predicting aerobic exercise participation: social cognitive, reasoned action, and planned behavior models. J. Sport Exerc. Psychol. 15, 363-374.

Zheng, Y., 2008. The benefit of public transportation: physical activity to reduce obesity and ecological footprint. Prev. Med. (Baltim). 46, 4-5. doi:10.1016/j.ypmed.2007.11.019 